\title{
EVIDENCE THAT A HUMORAL AGENT STIMULATES THE ADRENAL CORTEX TO SECRETE ALDOSTERONE IN EXPERIMENTAL SECONDARY HYPER- ALDOSTERONISM *
}

\author{
By NICHOLAS A. YANKOPOULOS, JAMES O. DAVIS, BERNARD KLIMAN AND \\ RALPH E. PETERSON WITH THE SURGICAL ASSISTANCE OF ALFRED CASPER \\ (From the Section on Experimental Cardiovascular Disease, Laboratory of Kidney and Electro- \\ lyte Metabolism, National Heart Institute and the National Institute of \\ Arthritis and Metabolic Diseases, Bethesda, Md.)
}

(Submitted for publication December 16, 1958; accepted April 2, 1959)

The mechanisms which effect alterations in the secretion of aldosterone by the adrenal cortex may be nervous, humoral or both. The present study was undertaken to examine the possibility that a humoral agent stimulates the adrenal cortex to secrete aldosterone in dogs with experimental secondary hyperaldosteronism produced by constriction of the thoracic inferior vena cava. These animals secrete large amounts of aldosterone (1) and show almost complete retention of $\mathrm{Na}$ (2). To test the hypothesis of a humoral mechanism, the effect on aldosterone secretion was studied in normal recipient animals or in the isolated adrenals of normal dogs during cross-circulation of blood from dogs with constriction of the thoracic inferior vena cava. Corticosterone secretion was also measured to evaluate the possible role of adrenocorticotropic hormone $(\mathrm{ACTH})$ in the aldosterone regulatory system.

\section{METHODS}

The basic plan of the experiments consisted of crosscirculation of blood from a donor into a recipient animal or into the isolated adrenal glands of a recipient animal. Secondary hyperaldosteronism was produced in the donor animals by either acute or chronic constriction of the thoracic inferior vena cava. Acute caval constriction was performed on normal dogs. In the chronic donor dogs, ascites had been present for one to three weeks, and $\mathrm{Na}$ excretion on the day before the experiment was less than $4 \mathrm{mEq}$. per day; $\mathrm{Na}$ and $\mathrm{K}$ intakes were 60 and $18 \mathrm{mEq}$. per day, respectively. Also, aldosterone secretion from the right adrenal gland was measured in a group of eight dogs with chronic thoracic inferior vena cava constriction to determine the magnitude and consistency of hypersecretion. All animals were mongrel dogs which weighed 15 to $20 \mathrm{Kg}$. Nembutal ${ }^{\circledR}$ anesthesia was used. Each dog received 15,000 I.U. of heparin before collection of adrenal vein blood and before cross-circulation.

* A preliminary report was given at the Laurentian Hormone Conference, September, 1958.
Two types of experiments were performed. In the first group of experiments (three pairs of dogs), crosscirculation was achieved through the femoral vessels by polyethylene tubing (i.d., $3.5 \mathrm{~mm}$.). Exchange of blood was regulated by screw clamps so that arterial and venous pressures remained similar to the values recorded before cross-circulation. Adrenal vein blood was collected from both animals from the right adrenal gland by cannulation of the right adrenolumbar vein as described previously (1). In the first pair of dogs, crosscirculation was performed between two normal animals. After control determinations in both animals, the thoracic inferior vena cava was constricted in one of the dogs which became the donor. In the two other experiments of this group, dogs with chronic thoracic caval constriction were the donor animals. Under these circumstances, control observations were made in both the chronic donor and the normal recipient before crosscirculation was established.

In the second group of experiments (15 pairs of dogs), blood was circulated from a donor animal with chronic thoracic caval constriction and ascites or from a normal dog into the isolated adrenals of a normal recipient animal (Figure 1). Cross-circulation of blood from normal dogs provided a control on the effect of cross-circulation per se. The recipient's adrenals were isolated in situ with segments of aorta and inferior vena cava by the procedure of Hilton and co-workers (3). Care was taken to include in the arterial circulation to the lower pole of the right adrenal gland a small artery arising from the aorta. Polyethylene tubing was used for all connections. During the control and recovery periods, blood was circulated from the recipient's carotid artery (autoperfusion) into the isolated aorta, through the adrenal glands, into the inferior vena cava and, subsequently, into the systemic circulation of the recipient by way of the external jugular vein. During the period of cross-circulation, blood perfused the isolated adrenals of the recipient from the femoral artery of the donor and returned to the donor's femoral vein. An infusion of norepinephrine (100 $\mu \mathrm{g}$. per ml.) was given in some instances (Tables I and II) during the latter part of the experiment to support arterial pressure and adrenal blood flow.

Collections of $10 \mathrm{ml}$. of adrenal vein blood and $10 \mathrm{ml}$. of peripheral blood were made at approximately one-half 


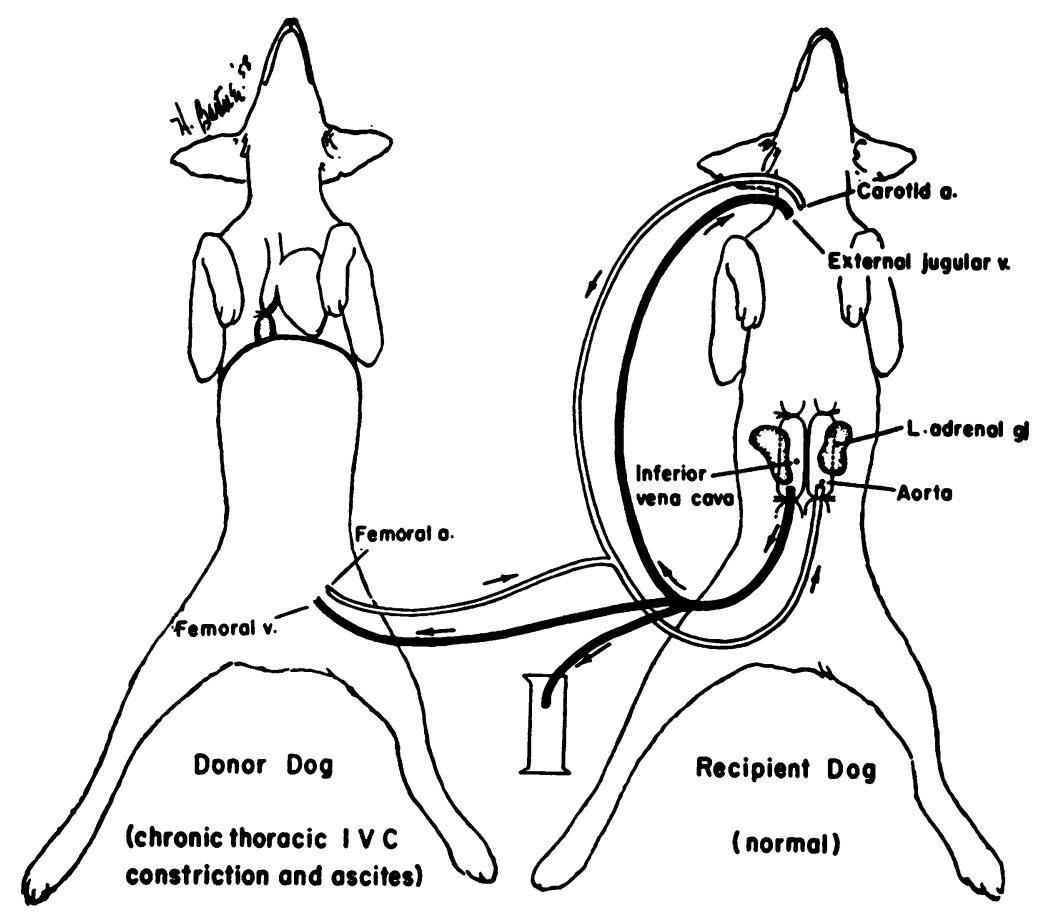

Fig. 1. Cross-Circulation of Blood from a Dog with Chronic Thoracic Inferior Vena Cava (IVC) Constriction into the Isolated Adrenals of a Normal Recipient Animal

hour intervals; blood was replaced immediately. Adrenal blood flow was measured by collection of blood into a graduated tube; the hematocrit was determined and adrenal plasma flow was calculated. The concentrations of aldosterone and corticosterone in adrenal vein plasma were determined and the rates of secretion calculated. The concentrations of plasma $\mathrm{Na}$ and plasma $\mathrm{K}$ were determined during cross-circulation of blood from dogs with hyperaldosteronism. Arterial and venous pressures were measured continuously with Statham strain gages and a Sanborn recording system. During crosscirculation via the femoral vessels, aortic and inferior vena caval pressures were determined in both donor and recipient animals. During perfusion of the isolated adrenals, pressures were recorded from the isolated segments of the aorta and inferior vena cava associated with the adrenals. The height of the animal table of the recipient dog was adjusted to maintain a constant venous pressure in the inferior vena cava or in the isolated segment of the inferior vena cava.

Procedure for the double isotope derivative assay for aldosterone and corticosterone. Aldosterone and corticosterone were measured in $3 \mathrm{ml}$. of adrenal vein plasma by the double isotope derivative procedure of Kliman, Peterson, Davis and Yankopoulos $(4,5)$. Each $3 \mathrm{ml}$. sample of plasma was extracted with $22 \mathrm{ml}$. of purified dichloromethane. The dichloromethane extract was washed successively with $2 \mathrm{ml}$. of $0.05 \mathrm{~N} \mathrm{NaOH}$ and with $2 \mathrm{ml}$. of $0.1 \mathrm{~N}$ acetic acid. The dichloromethane extract was dried at $37^{\circ} \mathrm{C}$. with a stream of nitrogen. The dried extract was transferred to a $6.5 \mathrm{ml}$. conical glass-stoppered tube with 2 to $3 \mathrm{ml}$. of absolute ethanol and two rinses of $2 \mathrm{ml}$. each of dichloromethane; the sample was dried with a stream of nitrogen. Each sample was acetylated with $0.03 \mathrm{ml}$. of tritium-labeled acetic anhydride (15 per cent acetic anhydride in dry benzene) in the presence of $0.025 \mathrm{ml}$. of anhydrous pyridine. The specific activity of the acetic anhydride was approximately $100 \mathrm{mc}$. per mMole. Each sample was incubated for 60 to 70 hours at $37^{\circ} \mathrm{C}$.; the acetylation tube was rotated on one occasion during incubation to insure complete acetylation. Aldosterone diacetate- $\mathrm{H}^{3}$, corticosterone monoacetate- $\mathrm{H}^{3}$ and the labeled acetates of other adrenal steroids were formed. About 2,000 cpm of aldosterone diacetate- $C^{14}$ in $0.1 \mathrm{ml}$. of ethanol and $5,000 \mathrm{cpm}$ of corticosterone monoacetate- $\mathrm{C}^{14}$ in $0.1 \mathrm{ml}$. of ethanol were added to each sample to correct for losses of aldosterone and corticosterone during all subsequent chromatographies. The exact number of $\mathrm{cpm}$ for each steroid in $0.1 \mathrm{ml}$. of ethanol was determined when the labeled steroids from the plasma samples were counted. Distilled water $(0.8 \mathrm{ml}$.) was added to each tube, extraction was carried out with about $5 \mathrm{ml}$. of dichloromethane and the dichloromethane extract was washed once with $1 \mathrm{ml}$. of distilled water. The dichloromethane was dried under a stream of air at $37^{\circ}$. Adrenosterone $(0.02 \mathrm{ml}$.) and corticosterone monoacetate $(0.02 \mathrm{ml}$.) in concentrations of $1 \mathrm{mg}$. per $\mathrm{ml}$. in absolute ethanol were added to each sample to provide a visible marker in ultraviolet light for aldosterone and enough corticosterone monoacetate for it to be visible. 
TABLE I

Effects of cross-circulation of blood from dogs with chronic thoracic inferior vena cava constriction into the isolated adrenals of normal dogs

\begin{tabular}{|c|c|c|c|c|c|c|c|c|c|}
\hline \multirow{2}{*}{$\begin{array}{l}\text { Dog } \\
\text { no. }\end{array}$} & \multicolumn{3}{|c|}{ Control } & \multicolumn{4}{|c|}{ Cross-circulation } & \multicolumn{2}{|c|}{ Recovery } \\
\hline & 1 & 2 & 3 & 1 & 2 & 3 & 4 & 1 & 2 \\
\hline \multicolumn{10}{|c|}{ Aldosterone secretion $(\mu \mathrm{g} . / \mathrm{min} .)^{*}$} \\
\hline $\begin{array}{r}4 \\
5 \\
6 \\
7 \\
8 \\
9 \\
9 \\
10\end{array}$ & $\begin{array}{l}.006 \\
.019 \\
.029 \\
.022 \\
.011 \\
.054 \\
.027\end{array}$ & $\begin{array}{l}.015 \\
.015 \\
.047 \\
.012 \\
.005 \\
.048 \\
.018\end{array}$ & $\begin{array}{l}.017 \\
.010 \\
.026 \\
.011 \\
.005 \\
.049\end{array}$ & $\begin{array}{l}.025 \\
.051 \\
.064 \\
.034 \\
.037 \\
.100 \\
.039\end{array}$ & $\begin{array}{l}.037 \\
.038 \\
.046 \\
.042 \\
.141 \\
.047\end{array}$ & $\begin{array}{l}.019 \\
.014 \\
.021 \\
.039 \\
.146 \\
.058\end{array}$ & $\begin{array}{l}.045 \\
.035\end{array}$ & $\begin{array}{l}.019 \\
.018 \\
.011 \\
.063 \\
.043\end{array}$ & $\begin{array}{l}.011 \\
.016 \\
.022 \\
.053 \\
.024\end{array}$ \\
\hline Mean & .024 & .023 & .020 & .050 & .059 & .050 & .040 & .031 & .025 \\
\hline \multicolumn{10}{|c|}{ Corticosterone secretion $(\mu \mathrm{g} . / \mathrm{min} .)^{*}$} \\
\hline $\begin{array}{r}5 \\
7 \\
8 \\
9 \\
10\end{array}$ & $\begin{array}{l}2.2 \\
2.7 \\
3.4 \\
2.0\end{array}$ & $\begin{array}{l}2.2 \\
2.2 \\
3.1 \\
3.2 \\
2.0\end{array}$ & $\begin{array}{l}1.9 \\
2.3 \\
3.2\end{array}$ & $\begin{array}{l}5.5 \\
3.1 \\
3.0 \\
4.6 \\
2.0\end{array}$ & $\begin{array}{l}3.0 \\
3.4 \\
\\
6.0 \\
2.3\end{array}$ & $\begin{array}{l}1.7 \\
2.6 \\
\\
5.6 \\
2.1\end{array}$ & $\begin{array}{l}3.3 \\
2.4\end{array}$ & $\begin{array}{l}1.5 \\
2.0 \\
2.2 \\
1.9\end{array}$ & $\begin{array}{l}1.0 \\
2.6 \\
\\
2.0 \\
1.1\end{array}$ \\
\hline Mean & 2.6 & 2.5 & 2.5 & 3.6 & 3.7 & 3.0 & 2.9 & 1.9 & 1.7 \\
\hline \multicolumn{10}{|c|}{ Adrenal blood flow (ml./min.)* } \\
\hline $\begin{array}{r}4 \\
5 \\
6 \\
7 \\
8 \\
9 \\
10\end{array}$ & $\begin{array}{r}7.40 \\
12.50 \\
11.30 \\
13.33 \\
10.75 \\
7.50 \\
7.50\end{array}$ & $\begin{array}{r}6.67 \\
11.33 \\
8.44 \\
7.41 \\
8.90 \\
6.17 \\
6.54\end{array}$ & $\begin{array}{r}5.50 \\
10.17 \\
7.70 \\
7.06 \\
7.10 \\
6.13 \\
5.81\end{array}$ & $\begin{array}{r}6.80 \\
16.24 \\
8.11 \\
10.00 \\
9.50 \\
12.00 \\
2.93\end{array}$ & $\begin{array}{r}3.22 \\
7.50 \\
4.80 \\
8.11 \\
11.76 \\
2.89\end{array}$ & $\begin{array}{r}1.84 \\
4.03 \\
3.33 \\
5.36 \\
13.60 \\
3.01\end{array}$ & $\begin{array}{l}9.60 \\
8.83\end{array}$ & $\begin{array}{r}10.52 \\
8.11 \\
7.06 \\
\\
4.59 \\
3.54\end{array}$ & $\begin{array}{l}7.69 \\
8.00 \\
8.00 \\
\\
3.57 \\
2.62\end{array}$ \\
\hline Mean & 10.04 & 7.92 & 7.07 & 9.37 & 6.38 & 5.19 & 9.21 & 6.76 & 5.98 \\
\hline
\end{tabular}

Mean arterial pressure $(\mathrm{mm} . \mathrm{Hg})^{*}$

$\begin{array}{rrrr}4 & 125 & 125 & 125 \\ 5 & 140 & 140 & 140 \\ 6 & 120 & 135 & 130 \\ 7 & 135 & 145 & 135 \\ 8 & 115 & 120 & 100 \\ 9 & 114 & 103 & 92 \\ 10 & 122 & 130 & 127 \\ \text { Mean } & 124 & 128 & 121\end{array}$

$\begin{array}{rcccrr}120 & 70 & 70 & & & \\ 125 & 95 & 90 & 130 \dagger & 200 & 170 \\ 95 & 100 \dagger & 100 \dagger & & 120 & 130 \\ 95 & 95 & 80 & 140 \dagger & 160 & 135 \\ 155 \dagger & & & & 98 & 90 \\ 100 & 96 & 87 & & 114 & 112 \\ 92 & 86 & 96 & & 138 & 127 \\ 112 & 90 & 87 & 135 & & \end{array}$

Venous pressure (mm. water)*

$\begin{array}{cccc}\mathbf{5} & \mathbf{5 5} & \mathbf{6 0} & 60 \\ \mathbf{6} & \mathbf{3 5} & 30 & 35 \\ \mathbf{7} & \mathbf{6 5} & \mathbf{6 5} & 55 \\ \mathbf{9} & \mathbf{9 0} & \mathbf{7 5} & 7 \\ \mathbf{9} & \mathbf{4 5} & \mathbf{5 0} & 5 \\ \mathbf{1 0} & \mathbf{6 5} & \mathbf{5 5} & 50 \\ \text { Mean } & \mathbf{5 9} & \mathbf{5 6} & 5\end{array}$

60
35
55
70
55
50
54

$\begin{array}{lll}40 & 30 & 25 \\ 30 & 45 & 50 \\ 55 & 50 & 70 \\ 50 & & \\ 45 & 30 & 30 \\ 35 & 20 & 15\end{array}$

$43 \quad 35 \quad 38$

$25 \quad 20$

$70 \quad 80$

$20 \quad 145 \quad 120$

$80 \quad 80 \quad 60$

$30 \quad 45 \quad 38$

54

Plasma Na (mEq./L.)

$\begin{array}{rlll}4 & 152 & 149 & 152 \\ 5 & 142 & 144 & 144 \\ 6 & 149 & 147 & 147 \\ 7 & 150 & 148 & 145 \\ 9 & 136 & 145 & 146 \\ 10 & 145 & 150 & 146\end{array}$

$\begin{array}{llllll}145 & 149 & 149 & 165 & & \\ 143 & 145 & 144 & 146 & 149 & 152 \\ 149 & 154 & 151 & & 152 & 151 \\ 140 & 149 & 149 & 146 & 146 & 150 \\ 140 & 141 & 146 & & 146 & 143 \\ 136 & 136 & 139 & & 144 & 147 \\ 142 & 146 & 146 & 152 & 147 & 149\end{array}$

* Steroid secretion, adrenal blood flow and arterial and venous pressures from isolated adrenals and associated vessels. $\dagger$ Norepinephrine infusion given to maintain arterial pressure and adrenal blood flow. 
TABLE I-Continued

\begin{tabular}{|c|c|c|c|c|c|c|c|c|c|}
\hline \multirow{2}{*}{$\begin{array}{l}\text { Dog } \\
\text { no. }\end{array}$} & \multicolumn{3}{|c|}{ Control } & \multicolumn{4}{|c|}{ Cross-circulation } & \multicolumn{2}{|c|}{ Recovery } \\
\hline & 1 & 2 & 3 & 1 & 2 & 3 & 4 & 1 & 2 \\
\hline \multicolumn{10}{|c|}{ Plasma K (mEq./L.) } \\
\hline $\begin{array}{r}4 \\
5 \\
6 \\
7 \\
9 \\
10\end{array}$ & $\begin{array}{l}3.4 \\
4.1 \\
3.9 \\
3.7 \\
3.2 \\
4.3\end{array}$ & $\begin{array}{l}3.8 \\
3.6 \\
3.2 \\
3.3 \\
3.0 \\
4.0\end{array}$ & $\begin{array}{l}3.6 \\
3.9 \\
3.0 \\
3.3 \\
2.8 \\
3.8\end{array}$ & $\begin{array}{l}3.4 \\
4.5 \\
3.9 \\
3.4 \\
2.9 \\
4.3\end{array}$ & $\begin{array}{l}4.0 \\
3.7 \\
4.0 \\
4.1 \\
2.6 \\
4.5\end{array}$ & $\begin{array}{l}3.7 \\
4.2 \\
4.7 \\
5.0 \\
4.1 \\
4.7\end{array}$ & $\begin{array}{l}3.7 \\
3.4 \\
\\
4.5\end{array}$ & $\begin{array}{l}2.8 \\
2.5 \\
5.5 \\
3.7 \\
4.0\end{array}$ & $\begin{array}{l}5.0 \\
3.9 \\
4.2\end{array}$ \\
\hline Mean & 3.8 & 3.5 & 3.4 & 3.7 & 3.8 & 4.4 & 3.9 & 3.7 & 4.4 \\
\hline
\end{tabular}

Each sample was transferred to Whatman No. 1 filter paper $(7.5 \times 22.5$ inches $)$ with four drops of absolute ethanol and eight to 10 drops of dichloromethane and chromatographed in a cyclohexane (100 parts), benzene (40 parts), methanol (100 parts) and water (20 parts) system by descending chromatography. After a minimal period of 45 minutes for equilibration, the chromatogram was developed at room temperature $\left(75^{\circ} \mathrm{F}\right.$.) for 16 to 18 hours by adding $90 \mathrm{ml}$. of the mobile phase. The paper was scanned with ultraviolet light, each spot of corticosterone monoacetate and adrenosterone was marked and areas of paper containing corticosterone monoacetate and aldosterone diacetate were cut out. The relation of adrenosterone to aldosterone diacetate had been previously ascertained by locating the position of aldosterone diacetate- $\mathrm{C}^{14}$ with a strip counter and the visible spot of adrenosterone by ultraviolet light. This relationship was checked periodically. The samples of corticosterone monoacetate and aldosterone diacetate were eluted into separate tubes with $10 \mathrm{ml}$. of absolute methanol. Both samples were dried.

For aldosterone, the second chromatography was carried out with a cyclohexane (100 parts), dioxane (100 parts), methanol ( 50 parts) and water (25 parts) system. The reference marker for aldosterone diacetate in this chromatographic system was 11-keto, 17ahydroxyprogesterone $(0.02 \mathrm{ml}$. of a $1 \mathrm{mg}$. per $\mathrm{ml}$. solution) ; the exact relation of the mobility of this steroid and aldosterone had been determined previously. The chromatogram was developed for 14 to 16 hours, the aldosterone diacetate was eluted with methanol and the sample was dried under air. To alter the mobility of the steroid and to insure better purification, each sample was treated with $0.1 \mathrm{ml}$. of 0.5 per cent chromic trioxide in glacial acetic acid. The tube was rotated to allow the chromate solution to wet the residue and allowed to stand for 10 minutes. The reaction was stopped with $2 \mathrm{ml}$. of 20 per cent absolute ethanol in water. Approximately $10 \mathrm{ml}$. of dichloromethane was added and each tube was shaken vigorously; the aqueous layer was aspirated and discarded. Each sample was washed twice with $1 \mathrm{ml}$. of distilled water and the dichloromethane was dried under an air. stream.

The third chromatography for the oxidation product of aldosterone diacetate was performed in a cyclohexane
(100 parts), benzene (50 parts), methanol (100 parts) and water (25 parts) system. The reference marker was $0.02 \mathrm{ml}$. of a $1 \mathrm{mg}$. per $\mathrm{ml}$. solution of $11 \alpha$ hydroxyprogesterone. The chromatogram was developed for 24 to 26 hours. Each sample of the oxidation product of aldosterone diacetate was eluted into a counting vial and dried under an air stream. To each vial, $5 \mathrm{ml}$. of a phosphor solution ( 0.4 per cent solution of 2,5-diphenyloxazole and 0.004 per cent solution of 1,4 , di-2-5 phenyloxazole in reagent grade toluene) was added.

A second chromatography for corticosterone monoacetate was performed with a cyclohexane (100 parts), dioxane (100 parts), methanol (50 parts) and water (25 parts) system. The chromatogram was developed for 12 to 15 hours. The corticosterone was eluted into counting vials, dried and the phosphor solution added.

The samples of aldosterone and of corticosterone were counted to determine the tritium and carbon- 14 radioactivity in a liquid scintillation spectrometer (Packard Tri-Carb Scintillation Spectrometer). Each sample was counted at a voltage of 890 (discriminator setting of 10 to 50 ) to determine the radioactivity of carbon-14 and at 1,270 volts (discriminator setting of $10-\infty$ ) to obtain the combined activity of carbon-14 and tritium. The number of tritium counts at 1,270 volts was obtained by subtracting the contribution of carbon-14 at this voltage from the total counts; the counts of carbon-14 at the high voltage were calculated from the ratio of pure carbon-14 counts at 1,270 volts to carbon- 14 counts at 890 volts. The quantity of aldosterone or corticosterone in a sample was calculated from the yield of tritium radioactivity, the amount of carbon-14 lost during chromatography and the specific activity of the tritium-labeled acetic anhydride.

The specific activity of the tritium-labeled acetic anhydride was determined by acetylating hydrocortisone and determining the specific activity of the acetylated steroid. Dry hydrocortisone $(0.5 \mathrm{mg}$.) was acetylated for 20 hours at room temperature with $0.02 \mathrm{ml}$. of tritium-labeled acetic anhydride in the presence of $0.02 \mathrm{ml}$. of anhydrous pyridine. After acetylation, $1 \mathrm{ml}$. of 20 per cent ethanol in water was added to the reaction mixture. The hydrocortisone acetate was extracted from the ethanol solution with five volumes of dichloromethane. The dichloromethane was washed with $1 \mathrm{ml}$. of distilled water and dried under an air stream. The sample of hydrocor- 
TABLE II

Effects of cross-circulation of blood from normal dogs into the isolated adrenals of normal animals

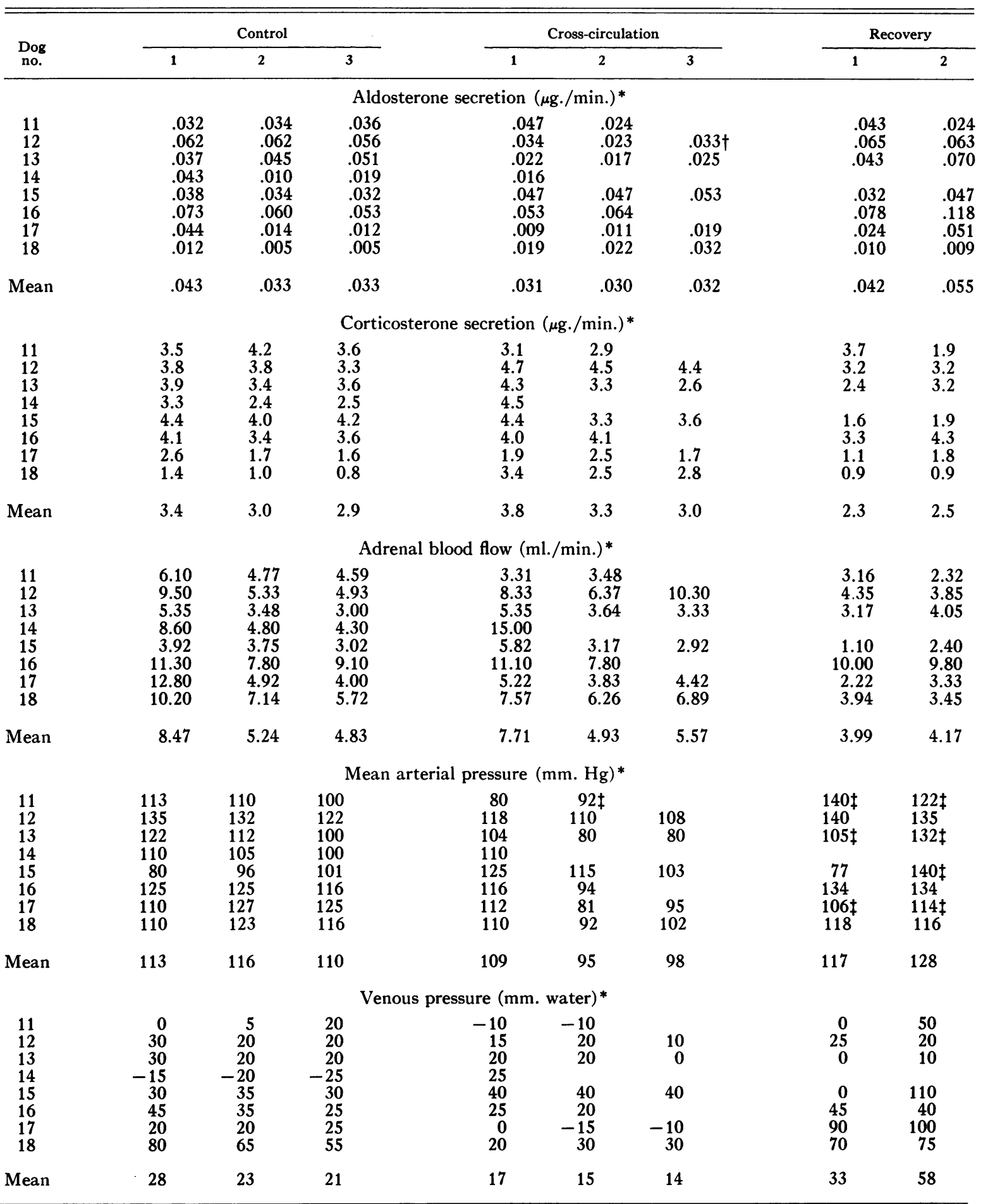

* Steroid secretion, adrenal blood flow and arterial and venous pressures from isolated adrenals and associated vessels. $\dagger$ The thoracic inferior vena cava was constricted for one hour and studies conducted between the experimental and recovery periods in this experiment (see Figure 4).

$\ddagger$ Norepinephrine infusion given to maintain arterial pressure and adrenal blood flow. 
tisone acetate was chromatographed on Whatman No. 1 paper for 15 to 18 hours in a carbon tetrachloride (100 parts), methanol (100 parts) and water (25 parts) system. The hydrocortisone acetate was eluted with ethanol and rechromatographed for 20 to 25 hours on alcohol washed paper in the second solvent system used for aldosterone. The hydrocortisone acetate was eluted with redistilled absolute ethanol and diluted to $25 \mathrm{ml}$. The concentration of hydrocortisone acetate in this eluate was measured by three methods: 1) absorption in the ultraviolet in a Beckman DU spectrophotometer at $242 \mathrm{~m} \mu$ $(\epsilon=15,850)$; 2) phenylhydrazine reaction in sulfuric acid-ethanol (Porter-Silber) (6); and 3) fluorometric assay with sulfuric acid-ethanol. The specific activity was determined by counting an aliquot of the eluate in the liquid scintillation spectrometer. The specific activity was expressed in terms of cpm per $\mu \mathrm{g}$. at the 1,270 voltage setting.

The aldosterone diacetate- $\mathrm{C}^{\mathbf{1 4}}$ was prepared from 1.0 $\mathrm{mg}$. of aldosterone. The aldosterone was acetylated for 44 hours at $37^{\circ} \mathrm{C}$. with acetic anhydride- $1-\mathrm{C}^{14}$ ( $5 \mathrm{mc}$. per mMole) in dry benzene (15 per cent) in the presence of anhydrous pyridine. The aldosterone diacetic- $\mathrm{C}^{\mathbf{1 4}}$ was partitioned between aqueous alcohol and dichloromethane as described previously and chromatographed on Whatman No. 1 paper in the first and second systems described previously for aldosterone. The steroid was eluted with redistilled ethanol and diluted to a volume such that each $0.1 \mathrm{ml}$. yielded approximately $2,000 \mathrm{cpm}$. The solution was stored at $-20^{\circ} \mathrm{C}$. where it remained stable for months.

The corticosterone monoacetate- $\mathrm{C}^{\mathbf{1 4}}$ was prepared from $2 \mathrm{mg}$. of corticosterone. Corticosterone was acetylated for 44 hours at $37^{\circ} \mathrm{C}$. with $0.02 \mathrm{ml}$. of acetic anhydride-1$\mathrm{C}^{14}$ ( $5 \mathrm{mc}$. per mMole) in benzene (15 per cent) in the presence of anhydrous pyridine. The corticosterone monoacetate- $\mathrm{C}^{14}$ was partitioned between aqueous alcohol and dichloromethane and chromatographed on Whatman No. 1 paper for 18 hours in the solvent system used for the first chromatography of aldosterone and corticosterone. The steroid was eluted, dried with a stream of nitrogen and chromatographed for 15 hours on the second solvent system used for aldosterone. The corticosterone was eluted with redistilled absolute ethanol and diluted to yield approximately $5,000 \mathrm{cpm}$ per $0.1 \mathrm{ml}$.

Specificity, reproducibility and recovery data for the double isotope derivative assay for aldosterone. Evidence for the specificity of this procedure for aldosterone was obtained by demonstrating the constancy of $\mathrm{H}^{3} / \mathrm{C}^{14}$ ratios for each sample with repeated chromatography. Aldosterone was added to each of the eight samples of pooled adrenal vein plasma in amounts to produce four levels of concentration (Table III); assays were carried out at each level and on the same pool of adrenal vein plasma with no added aldosterone. The $\mathrm{H}^{2} / \mathrm{C}^{14}$ ratio was determined after each of the three chromatographies by determining tritium and carbon counts from an aliquot of the eluate at the 1,270 voltage setting. The solvent systems and time for development of the chromatograms were the same as those described previously for aldosterone. The ratio of $\mathrm{H}^{3} / \mathrm{C}^{14}$ was essentially the same after the second and third chromatographies (Table III). This finding indicates that no tritium-labeled impurities were present after the second chromatography. Nevertheless, a third chromatography has been used in all routine studies. Recovery data on the same plasma samples are presented in Table III.

A similar study of the specificity of this technique for corticosterone was made. The first two chromatographies were the same as those used for corticosterone in routine

TABLE III

Recovery, reproducibility and specificity data for aldosterone with the double isotope derivative assay procedure

\begin{tabular}{|c|c|c|c|c|c|c|c|}
\hline \multirow[b]{3}{*}{ Sample } & \multicolumn{4}{|c|}{ Aldosterone recoveries } & \multirow{2}{*}{\multicolumn{3}{|c|}{$\begin{array}{l}\text { Purification during chromatography } \\
\mathrm{H}^{3} / \mathrm{C}^{14} \text { after each chromatography }\end{array}$}} \\
\hline & \multirow{2}{*}{$\begin{array}{l}\text { Aldosterone } \\
\text { added* }\end{array}$} & \multirow{2}{*}{$\begin{array}{l}\text { Determined } \\
\text { aldosterone }\end{array}$} & \multirow{2}{*}{$\begin{array}{l}\text { Recovery of } \\
\text { aldosterone } \\
\text { added }\end{array}$} & \multirow{2}{*}{$\begin{array}{c}\% \\
\text { Recovery } \dagger\end{array}$} & & & \\
\hline & & & & & 1st & 2nd & 3rd \\
\hline & $\underset{\text { plasma }}{\text { Mg. } / \mathrm{ml} \text {. of }}$ & $\mu g . / m l$. & $\mu g . / m l$. & & & & \\
\hline $\mathrm{N}^{*}$ & & .025 & & & 21.1 & 2.14 & 2.32 \\
\hline $1 \mathrm{~A}$ & $.012-.015$ & .039 & .014 & 104 & 34.7 & 4.18 & 4.40 \\
\hline B & $.012-.015$ & .041 & .016 & 119 & 15.0 & 1.88 & 2.21 \\
\hline $2 \mathrm{~A}$ & $.024-.030$ & .047 & .022 & 82 & 36.4 & 5.58 & 5.28 \\
\hline B & $.024-.030$ & .052 & .027 & 100 & 17.2 & 2.67 & 2.90 \\
\hline $3 \mathrm{~A} \S$ & $.040-.050$ & .075 & .050 & 111 & 18.0 & 3.75 & 4.03 \\
\hline B & $.040-.050$ & .065 & .040 & 89 & 16.8 & 3.36 & 3.47 \\
\hline $4 \mathrm{~A} \S$ & $.080-.100$ & .105 & .080 & 89 & 16.6 & 5.77 & 5.62 \\
\hline $\mathrm{B}$ & $.080-.100$ & .111 & .086 & 96 & 15.3 & 6.13 & 5.96 \\
\hline
\end{tabular}

* Three $\mathrm{ml}$. of the same pool of adrenal vein plasma from the isolated adrenals of a normal dog were used for each sample. No aldosterone was added to Sample N. The concentration of the aldosterone added was determined by measuring a stock solution in the ultraviolet at $242 \mathrm{~m} \mu(\epsilon=15,850)$. The higher values given represent added aldosterone calculated on this basis. The lower values were calculated from data obtained by double isotope derivative analysis of the same stock solution of aldosterone after addition to plasma (see Table IV).

$\dagger$ Per cent recovery is calculated by use of the average of the two values for aldosterone from Column 2 .

$\pm \mathrm{H}^{3} / \mathrm{C}^{14}$ is the ratio of the cpm of $\mathrm{H}^{3}$ and $\mathrm{C}^{14}$ at the 1,270 voltage setting; see text.

$\$$ Five thousand $\mathrm{cpm}$ of corticosterone monoacetate-C ${ }^{14}$ was added initially to provide an artificial contaminant of the sample. 
TABLE IV

Reproducibility of aldosterone determinations in plasma

\begin{tabular}{ccc}
\hline \hline $\begin{array}{c}\text { Lots of } \\
\text { tritium- } \\
\text { labeled } \\
\text { acetic } \\
\text { anhydride }\end{array}$ & \multicolumn{1}{c}{$\begin{array}{c}\text { Aldosterone in each } \\
\text { sample }\end{array}$} & $\begin{array}{c}\text { Average value } \\
\text { for aldosterone } \\
\text { for each lot } \\
\text { of acetic } \\
\text { anhydride }\end{array}$ \\
\hline & \multicolumn{1}{c}{$\mu \mathrm{gg} / \mathrm{ml}}$. & $\mu \mathrm{\mu g} / \mathrm{ml}$. \\
1 & $.063, .071, .072, .062$ & .067 \\
2 & $.076, .069$ & .073 \\
3 & $.079, .081, .077$ & .079 \\
4 & $.077, .082, .075$ & .078 \\
5 & $.103, .082, .092, .080, .100$ & .091 \\
6 & .080 & .080
\end{tabular}

Mean $=0.079 \pm .011 \mathrm{~S}$. D. $\quad$ Mean $=.078 \pm .008 \mathrm{~S}$. D.

analyses. The samples were then oxidized with chromic trioxide as for aldosterone except for only five minutes; corticosterone monoacetate was converted to 11-dehydrocorticosterone acetate. The first solvent system was used for the third chromatography and the chromatogram was developed 14 to 16 hours. The ratio of $\mathrm{H}^{3} / \mathrm{C}^{14}$ was unchanged after the second chromatography. The data indicate that only two chromatographies were needed for purification at the concentrations of corticosterone observed in the present study.

Data on reproducibility are presented for duplicate samples of plasma aldosterone analyzed concurrently (Table III); the agreement is satisfactory. Similar results were obtained for corticosterone. Additional data on reproducibility have been obtained by analyzing one sample of plasma for aldosterone with each weekly group of 10 to 15 samples of adrenal vein plasma from an experiment. A pool of $150 \mathrm{ml}$. of peripheral plasma to which aldosterone had been added was the source for each control sample which was analyzed weekly. Six different lots of tritium-labeled acetic anhydride were used and analyses were performed weekly over a period of five months. The results are presented in Table IV. The mean value for the 18-aldosterone determinations with six lots of acetic anhydride was $0.079 \pm 0.011 \mu \mathrm{g}$. per $\mathrm{ml}$.

\section{RESULTS}

Cross-circulation of blood from dogs with thoracic caval constriction into normal recipients via the femoral vessels

Aldosterone secretion increased in two of the three recipient dogs following cross-circulation of blood from a donor dog with thoracic caval constriction (Table V). During study of the first pair of animals, acute constriction of a normal dog which became the donor resulted in a 175 per cent increase (comparison of average control with average experimental value) in aldosterone secre- tion while a 251 per cent elevation in aldosterone production occurred in the recipient animal. In the second pair of dogs, aldosterone secretion in the chronic donor animal with thoracic caval constriction was markedly elevated above the average rate of aldosterone secretion for normal dogs (Table V, Figure 2) ; during cross-circulation, aldosterone secretion was not altered appreciably in the donor. In the normal recipient dog of this pair, a 146 per cent increase in aldosterone secretion occurred during cross-circulation. Failure of a response to occur in the third recipient may be a reflection of the abnormally high control values of 0.077 to $0.142 \mu \mathrm{g}$. per minute in the recipient; the initial hematocrit in this animal was 39 per cent which was considerably lower than the hematocrit for the other dogs. It seems likely that the initial high values for aldosterone resulted from intra-abdominal bleeding.

The alterations in corticosterone secretion were slight and variable. In the first pair of dogs, the values of corticosterone secretion in the recipient were 33 per cent higher during cross-circulation than during the control period. Also, in the donor a similar slight increase in corticosterone secretion occurred. In the other four animals, corticosterone secretion was either unchanged or fell slightly in both donor and recipient.

The changes in adrenal blood flow after acute

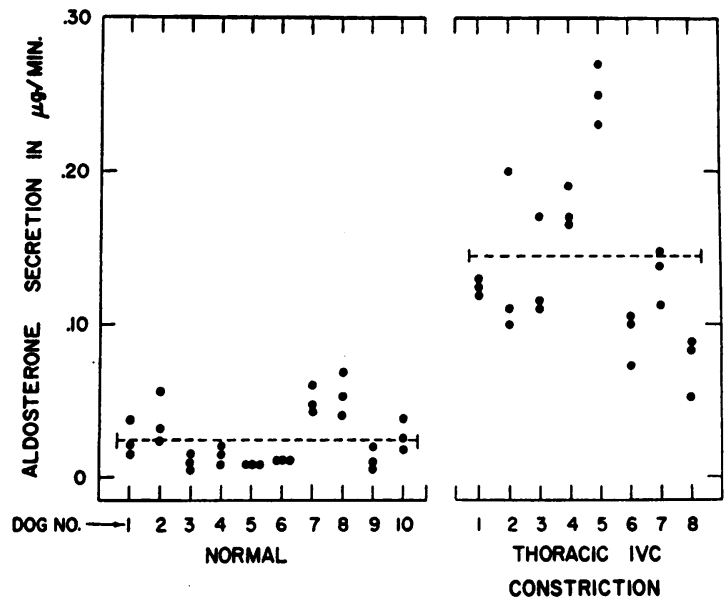

Fig. 2. The Rates of Aldosterone Secretion in Adrenal Vein Plasma from the Right Adrenal Gland of Normal Dogs and from Dogs with Chronic Thoracic Inferior Vena Cava (IVC) Constriction

The three determinations for each animal were made at 30 minute intervals. 
EVIDENCE FOR AN ALDOSTERONE STIMULATING HORMONE

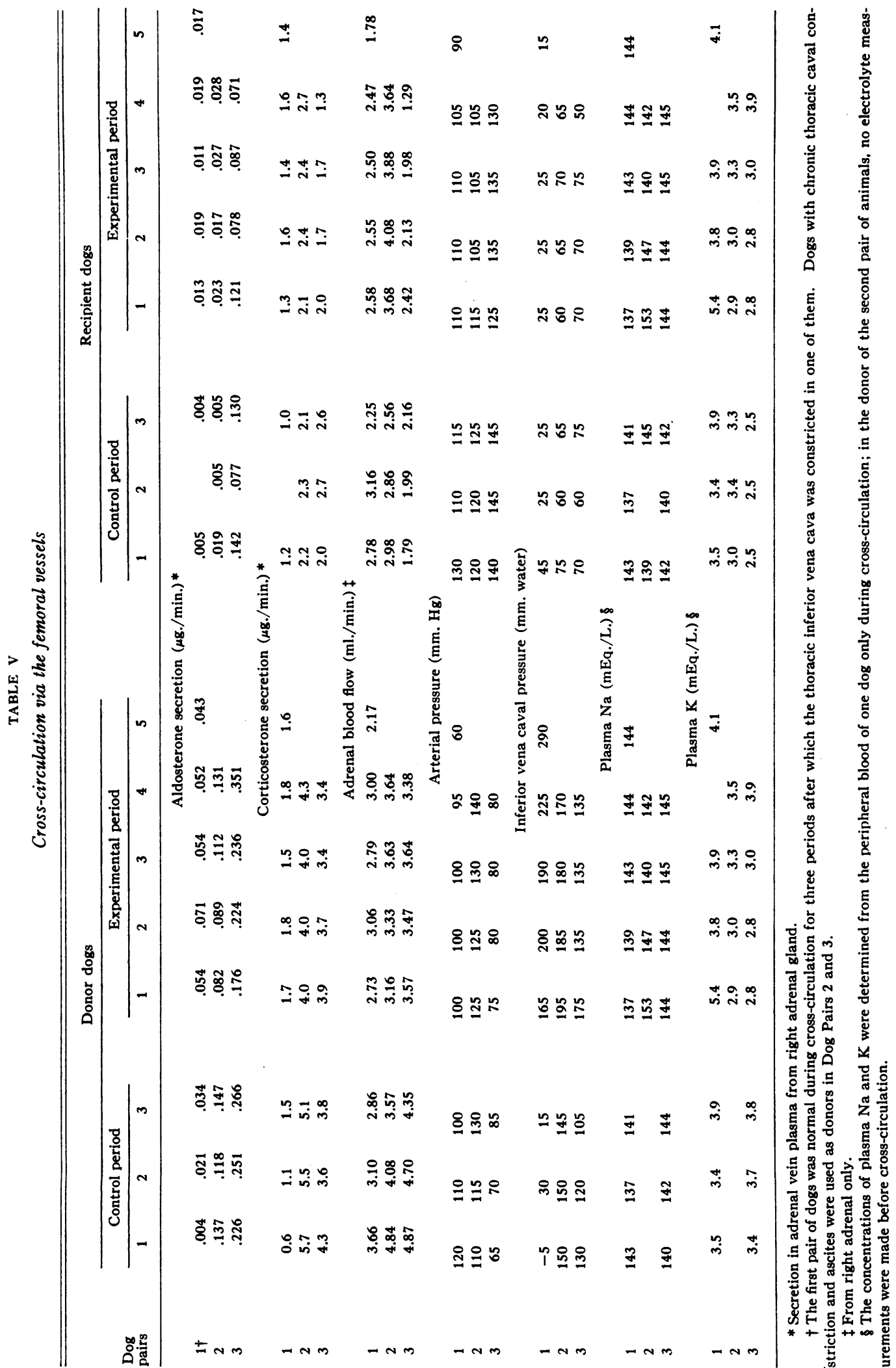




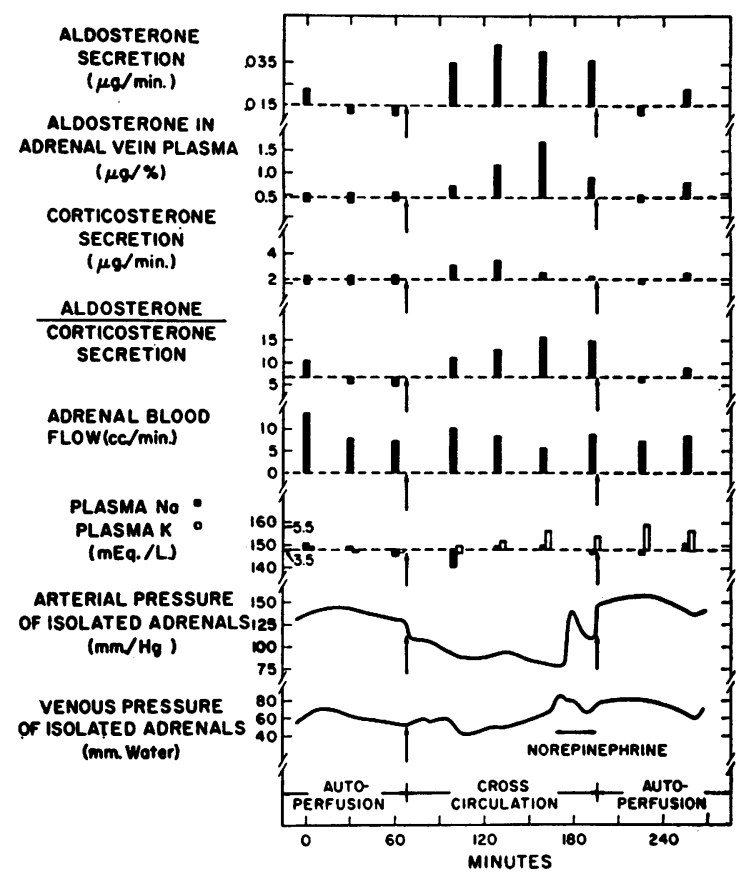

Fig. 3. The Effects of Circulation of Blood from a Dog with Chronic Thoracic Caval Constriction into the Isolated Adrenals of a Normal Recipient Animal (Dog No. 7 in Table I)

The actual $\frac{\text { aldosterone }}{\text { corticosterone }}$ ratio is multiplied by $10^{3}$.

caval constriction or after establishment of crosscirculation were slight and apparently were without effect on hormone secretion (Table V). Inferior vena caval pressure increased in the donor dog only in the first pair of animals, and the high venous pressure present in the other donor dogs with chronic thoracic caval constriction increased further during cross-circulation while venous pressure in the recipient animals was maintained at the control level. Only slight fluctuations in arterial pressure occurred. No consistent alterations in plasma $\mathrm{Na}$ or $\mathrm{K}$ were detected.

Circulation of blood from dogs with chronic constriction of the thoracic inferior vena cava through the isolated adrenals of normal recipient animals

Observations were first made on a group of eight dogs with chronic thoracic caval constriction, ascites and marked $\mathrm{Na}$ retention to determine by the present radioisotope technique the magnitude and consistency of hypersecretion of aldosterone.
The data that were obtained are compared (Figure 2) with those reported previously (5) for normal dogs. Aldosterone secretion was elevated in every animal with caval constriction and the mean rate of aldosterone secretion of $0.146 \mu \mathrm{g}$. per minute for dogs with caval constriction was sixfold greater than the average rate of $0.024 \mu \mathrm{g}$. per minute for normal dogs $(t=5.8 ; p<0.001)$. It was concluded that the consistency and magnitude of the hyperaldosteronism was sufficient to justify performance of cross-circulation without measurements of aldosterone secretion in the chronic donor dogs.

Seven cross-circulation experiments were conducted using dogs with chronic thoracic caval constriction as donors (Table I). After three control determinations during autoperfusion of the recipient's isolated adrenals, cross-circulation was established with a dog with chronic thoracic caval constriction. In five of the seven experiments, a recovery period with autoperfusion was obtained.

Aldosterone secretion increased in every instance (average increase was 129 per cent) and returned to the control level during the recovery periods (Table I, Figure 3). A statistical analysis of variance showed that the increase was significant at the 1 per cent level $(F=14.50, t=$ 3.80 ). The increase in aldosterone secretion was associated with a greater increase percentage-wise (196 per cent) in the concentration of aldosterone in adrenal vein plasma. Since blood from the donor dogs perfused isolated adrenal glands, the data show a direct effect upon the recipient's adrenals of a humoral agent in donor blood. The rate of corticosterone secretion was slightly higher during cross-circulation in three of the five experiments and fell during the recovery period. Variations in adrenal blood flow occurred and the low values for aldosterone secretion for the third determination during the cross-circulation period in Dogs 4, 5 and 6 were associated with low adrenal blood flows (Table I). Arterial pressure was slightly lower during cross-circulation than during control and recovery periods unless the pressure was maintained by a norepinephrine infusion. Inferior vena caval pressure was unchanged or slightly reduced during cross-circulation and slightly elevated during recovery. No consistent changes in plasma $\mathrm{Na}$ were detected during cross-circulation. Plasma $\mathrm{K}$ was un- 
changed or increased slightly during cross-circulation; in one instance (Figure 3 ) the slight increase continued during recovery.

Circulation of blood from normal dogs into the isolated adrenals of normal recipient animals

To determine the effects of cross-circulation per $s e$ on adrenocortical function, eight studies were performed by circulation of blood from a normal animal into the isolated adrenals of a normal recipient. Aldosterone secretion remained unchanged or decreased in all but two dogs and the mean values for aldosterone secretion were unchanged (Table II). During recovery, aldosterone production was slightly elevated in some instances. The variable response is probably attributable to factors producing variation in aldosterone secretion in the normal donors. Corticosterone output was increased slightly (four dogs) or unchanged (four dogs) during cross circulation (Table II, Figure 4) and decreased during recovery. Adrenal blood flow was not appreciably different during the control and cross-circulation periods but was slightly reduced during recovery. The slight decline in arterial pressure was similar to that observed during cross-circulation of blood from dogs with secondary hyperaldosteronism into normal isolated adrenals. Inferior vena caval pressure was unchanged during cross-circulation but was frequently slightly elevated during recovery. In one experiment (Figure 4), the thoracic inferior vena cava was constricted in the normal donor after three determinations had been made during cross-circulation; a 100 per cent increase in aldosterone secretion resulted. The data for arterial and venous pressures and adrenal blood flow on this animal are presented in Table II (see Dog No. 12).

\section{DISCUSSION}

The mechanisms regulating aldosterone secretion by the adrenal cortex may be neural, humoral or both. That neural connections to the adrenal gland are unnecessary for aldosterone secretion and maintenance of electrolyte metabolism was suggested more than two decades ago by Levy and Blalock (7). They transplanted one adrenal gland to the neck and removed the other adrenal;

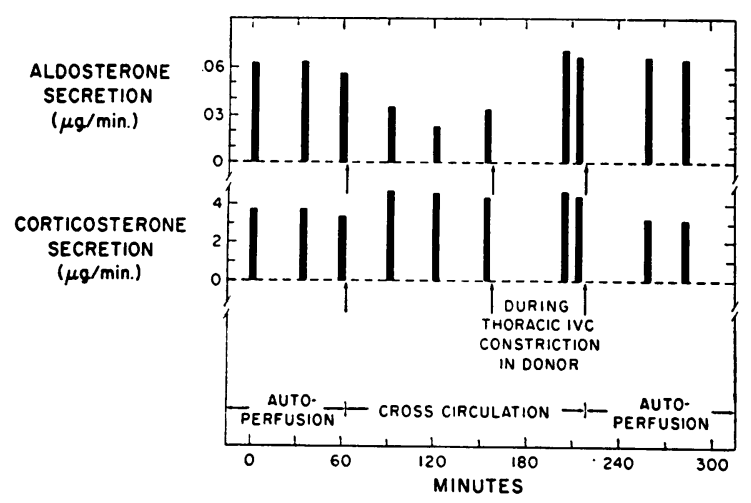

Fig. 4. Aldosterone and Corticosterone Secretion from Normal Isolated Adrenals Before (AUtoperfusion) and During Cross-Circulation of Blood from a Normal Dog

Subsequently, the thoracic inferior vena cava in the normal animal was constricted. A recovery period was obtained with the recipient's blood (autoperfusion).

several animals lived for months in a normal healthy condition. More recently, Fleming and Farrell (8) showed that acutely transplanted adrenals secrete normal or above normal amounts of aldosterone. Additional data were provided by McDonald, Goding and Wright (9) from chronic studies in unanesthetized sheep. Unilaterally adrenalectomized sheep with the remaining adrenal transplanted to the neck showed maintenance of normal plasma electrolyte concentrations and a normal response to $\mathrm{Na}$ depletion as indicated by a marked drop in the salivary $\mathrm{Na}: \mathrm{K}$ ratio. If a humoral mechanism is involved, it might be an alteration in the concentrations of plasma electrolytes, or it might be hormonal. Slight fluctuations in plasma $\mathrm{Na}$ and $\mathrm{K}$ occurred in the present study but no consistent changes were detected. Measurements of total plasma osmolality in previous studies of dogs with acute thoracic inferior vena cava constriction and hyperaldosteronism (5) showed no change.

The present experiments demonstrate that blood from dogs with secondary hyperaldosteronism stimulated aldosterone secretion in normal recipient animals and in the isolated adrenals of normal dogs. The increase was associated with an elevation in the concentration of aldosterone in adrenal vein plasma. During the preliminary study of the effects of cross-circulation via the femoral vessels, the volume of blood in both donor 
and recipient animals was regulated by means of screw clamps on the interconnecting tubing in an attempt to maintain a constant arterial pressure. Since changes in blood volume could not be excluded, the definitive study was performed by cross-circulation of blood from dogs with thoracic caval constriction into the isolated adrenals of normal dogs. As a control on the effects of cross-circulation per se or for any event associated with this experimental design, blood from normal dogs was circulated through normal isolated adrenals. Arterial pressure fell slightly during cross-circulation in most experiments but the decline in pressure was essentially the same for both experimental (Table I) and control (Table II) groups. The arterial pressure in the donor animals was the same as the recorded pressure of blood which perfused the isolated adrenals since the blood pressure in the isolated aorta was derived entirely from blood from the donor. Aldosterone secretion increased in every instance and the change was highly significant during cross-circulation of blood from hyperaldosteronemic donors into isolated adrenals, whereas crosscirculation of blood from normal animals produced no consistent alteration in aldosterone secretion and the mean control and mean experimental values were the same. The present study demonstrates, therefore, the existence of an aldosterone stimulating agent in blood of dogs with experimental secondary hyperaldosteronism and it is suggested that this humoral agent is a hormone. The data agree with the suggestion of Orti, Ralli, Laken and Dumm (10) that a humoral substance provides the stimulus to aldosterone production. Orti and associates reported evidence from studies of rats on a low $\mathrm{Na}$ diet that a substance in urine increased aldosterone excretion in feces.

In most of the present experiments, corticosterone secretion was measured to examine the possibility that the circulating hormone is ACTH. Corticosterone rather than hydrocortisone was studied because of the similar polarity of corticosterone monoacetate and aldosterone diacetate during descending chromatography; these two steroids were separated with the same solvent system during the first chromatography. In the dog, the effects of ACTH on corticosterone and hydrocortisone release are very similar. Farrell, Rauschkolb and Royce (11) showed similar marked drops in corticosterone and hydrocortisone after hypophysectomy and an increase in both steroids after ACTH administration. This marked drop in corticosterone after hypophysectomy in the dog and the response to ACTH have been confirmed (Reference 12, and unpublished observations). Also, in an earlier report (5), concurrent measurements of Porter-Silber reacting steroids and corticosterone in adrenal vein plasma showed similar directional changes in every instance. Available evidence indicates, therefore, that alterations in either corticosterone or hydrocortisone secretion may reflect changes in circulating ACTH in the dog.

Increased circulating $\mathrm{ACTH}$ alone does not appear to explain the observed increase in aldosterone output. Aldosterone secretion increased markedly in every instance during cross-circulation of blood from dogs with secondary hyperaldosteronism into isolated adrenal whereas corticosterone secretion increased slightly in 60 per cent of the experiments. During the present recovery observations, aldosterone secretion was at the control level or slightly elevated whereas corticosterone output declined further and in many instances this decline was associated with a decrease in adrenal blood flow. In one experiment (Figure 4) in which blood from a normal dog was circulated through normal isolated adrenals, aldosterone secretion fell while corticosterone output increased; subsequent constriction of the thoracic inferior vena cava of the normal donor resulted in a 100 per cent increase in aldosterone production but corticosterone secretion was unchanged. Also, the alterations in corticosterone secretion were similar during cross-circulation of blood from normal dogs into isolated adrenals to the changes found during cross-circulation of blood from dogs with chronic caval constriction. During previous observations (5), acute constriction of the thoracic inferior vena cava produced an increase in aldosterone secretion while corticosterone output fell. Although these findings suggest different regulatory mechanisms for aldosterone and corticosterone secretion, the data do not exclude an influence of ACTH on aldosterone production. Both aldosterone and corticosterone output may have been increased during the control observations as a result of surgery. Hilton and associates (3) have reported near maximal output of hydrocortisone in the isolated adrenal preparation. Additional stud- 
ies are needed to identify this aldosterone stimulating substance and to determine its origin.

\section{SUMMARY AND CONCLUSIONS}

To test the possibility of a humoral mechanism in the regulation of aldosterone secretion, crosscirculation experiments were performed between dogs with thoracic inferior vena cava constriction and secondary hyperaldosteronism and normal recipient animals. Cross-circulation was established through the femoral vessels, or the isolated adrenals of normal animals were perfused with blood from a hyperaldosteronemic donor. Control and recovery periods were obtained with the recipient's blood or by cross-circulation of blood from a normal dog. Repeated determinations of aldosterone and corticosterone were made in adrenal vein plasma by the double isotope derivative method. Aldosterone secretion in the recipient or in the recipient's isolated adrenals increased markedly in nine of 10 experiments, and returned to the control level in the isolated adrenals of five dogs with recovery observations. Corticosterone secretion increased only slightly in four of eight experiments. No consistent alterations in the concentrations of plasma $\mathrm{Na}$ and $\mathrm{K}$ were detected. During crosscirculation of blood from eight normal dogs into the isolated adrenals of normal animals, aldosterone secretion was unchanged or decreased in all but two dogs; a slight increase in corticosterone secretion occurred in one-half of the animals. It is concluded that a humoral agent, possibly a hormone, stimulates the adrenals to secrete aldosterone in dogs with secondary hyperaldosteronism.

\section{ACKNOWLEDGMENTS}

We are indebted to Dr. J. E. Lieberman for the statistical analysis of variance.

\section{REFERENCES}

1. Davis, J. O., Pechet, M. M., Ball, W. C., Jr., and Goodkind, M. J. Increased aldosterone secretion in dogs with right-sided congestive heart failure and in dogs with thoracic inferior vena cava constriction. J. clin. Invest. 1957, 36, 689.

2. Davis, J. O., and Howell, D. S. Mechanisms of fluid and electrolyte retention in experimental preparations in dogs. II. With thoracic inferior vena cava constriction. Circulat. Res. 1953, 1, 171.

3. Hilton, J. G., Weaver, D. C., Muelheims, G., Glaviana, V. V., and Wegria, R. Perfusion of the isolated adrenals in situ. Amer. J. Physiol. 1958, 192, 525.

4. Kliman, B., and Peterson, R. E. Isotope derivative assay of aldosterone in biological extracts. Fed. Proc. 1958, 17, 255.

5. Davis, J. O., Kliman, B., Yankopoulos, N. A., and Peterson, R. E. Increased aldosterone secretion following acute constriction of the inferior vena cava. J. clin. Invest. 1958, 37, 1783.

6. Peterson, R. E., Karrer, A., and Guerra, S. L. Evaluation of Silber-Porter procedure for determination of plasma hydrocortisone. Analyt. Chem. 1957, 29, 144.

7. Levy, S. E., and Blalock, A. A method for transplanting the adrenal gland of the dog with reestablishment of its blood supply. Ann. Surg. 1939, 109, 84.

8. Fleming, R., and Farrell, G. Aldosterone and hydrocortisone secretion by the denervated adrenal. Endocrinology 1956, 59, 360.

9. McDonald, I. R., Goding, J. R., and Wright, R. D. Transplantation of the adrenal gland of the sheep to provide access to its blood supply. Aust. J. exp. Biol. med. Sci. 1958, 36, 83.

10. Orti, E., Ralli, E. P., Laken, B., and Dumm, M. E. Presence of an aldosterone stimulating substance in the urine of rats deprived of salt. Amer. J. Physiol. 1957, 191, 323.

11. Farrell, G. L., Rauschkolb, E. W., and Royce, P. C. Secretion of aldosterone by the adrenal of the dog. Amer. J. Physiol. 1955, 182, 269.

12. Davis, J. O., Bahn, R. C., Yankopoulos, N. A., Kliman, B., Peterson, R. E., and Ball, W. C., Jr. Effects of acute and chronic hypothalamic lesions on aldosterone secretion in dogs with chronic experimental ascites. The Physiologist 1958, 1, 15. 